\title{
Multiattribute decision making for the assessment of disaster resilience in the Three Gorges Reservoir Area
}

\author{
Yuying Yang $^{1}$, Haixiang Guo $^{1,2,3}$, Linfei Chen $^{1}$, Xiao Liu $^{1}$, Mingyun Gu $^{1}$ and Wenwen Pan $^{1}$
}

\begin{abstract}
Disaster resilience assessments are critical to both urban and rural development, especially in disaster-prone regions. The Three Gorges Reservoir Area is a typical disaster-prone area, but there is a lack of research on disaster resilience in this area. We proposed a set of indicators and methodologies as a development of a comprehensive disaster resilience evaluation index system that encompasses societal, economic, natural environment, and infrastructure perspectives. Then an integrated approach, which combines 3 weight value determination methods, 6 evaluation methods, and 3 sorting methods, was developed and applied to disaster resilience assessments of 17 counties in the Three Gorges Reservoir Area, from which a final ranking was obtained. The conclusions we got from the research are: (1) the overall disaster resilience in the Three Gorges Reservoir Area is relatively low; (2) the disaster resilience in the Three Gorges Reservoir Area has significant regional differences, as well as social, economic, infrastructural, and environmental resilience; and (3) the societal, economic, and natural environment resilience all have a certain correlation with disaster resilience. Finally, suggestions were given to improve the disaster resilience in the Three Gorges Reservoir Area. This study can provide a framework and method for disaster resilience assessment.
\end{abstract}

Key Words: China; disaster resilience assessment; multiattribute decision-making method; resilience indicators.

\section{INTRODUCTION}

As intensive human activities have led to substantial global climate change, natural hazards have become more and more frequent and intensive causing significant damage to the society, economy, infrastructure, and environment (Galindo and Batta 2013, Aghakouchak et al. 2018). As can be seen from Figure 1, from 1998-2017, direct economic and societal losses in disasterhit countries were US\$2908 billion, with 1.3 million deaths, and 4.4 billion injured, homeless, or in need of emergency assistance (Wallemacq 2018). Therefore, reducing the risk of natural disasters has become a significant challenge for most countries and regions. Progress in disaster risk reduction research has shown that it is often not the hazard that determines a disaster, but the vulnerability, exposure, and the lack of disaster resilience (AitsiSelmi et al. 2015). Clear scientific and objective quantification of disaster resilience can inform the formulation of appropriate resilience improvement policies. The assessment of disaster resilience is a topic of significant importance (Aldrich 2012, Kythreotis and Bristow 2017), especially for developing countries with frequent disasters and large losses (UNISDR 2015).

Fig. 1. Top five countries/regions for disaster losses from 1998 and 2017.

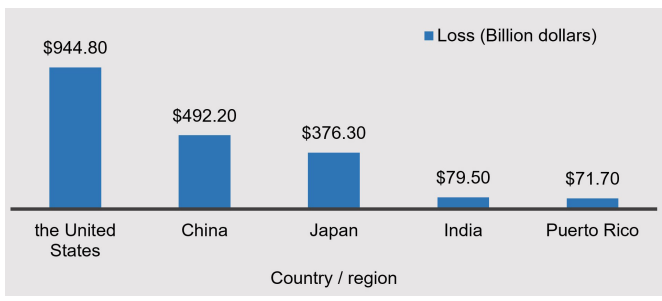

China is the largest developing country in the world with complicated natural conditions and often suffers from different natural disasters, especially landslides, floods, earthquakes, and storms (Liu et al. 2018). The economic losses caused by disasters are second only to those in the United States (Wallemacq 2018). The Chinese government has attached great importance to strengthening disaster management and disaster prevention to improve disaster reduction and relief capabilities in disaster-prone areas. The Three Gorges Reservoir Area in China is a typical disaster-prone area that suffers from frequent geological disasters and is characterized by serious soil erosion, intense agricultural activity, and poor economy (Zhou et al. 2010, Ma et al. 2015, Peng et al. 2019). In addition, large-scale dam projects have a range of social impacts, including: the migration and resettlement of people near the dam sites; changes in the rural economy and employment structure; effects on infrastructure and housing; and so on (Tilt et al. 2009). An empirical study by Tilt and Gerkey (2016) found that population resettlement caused by dams may lead to a decrease in resilience. Therefore, disaster resilience assessment for the Three Gorges Reservoir Area is very essential to locate any weaknesses, which would help to enhance its disaster resilience. However, previous studies on the area mainly focused on geological disasters (Bai et al. 2010), environmental change (Tan and Yao 2006), and poverty (Xu et al. 2017, Cheng et al. 2018, Peng et al. 2019), and comparative studies on disaster resilience in a holistic and comprehensive manner are few.

Vulnerability and resilience assessments of natural hazards have emerged in the past decades as an important research field (Birkmann et al. 2013, Fekete et al. 2014, Saja et al. 2019). Although vulnerability and resilience assessments share the same purpose, i.e., to reduce disaster risk, they are overlapping but different concepts (Kelman et al. 2016). Disaster resilience is the ability to reduce loss, recover, and adapt from a crisis or disaster

${ }^{1}$ School of Economics and Management, China University of Geosciences, Wuhan, P. R. China, ${ }^{2}$ School of Management, Xi'an University of Finance and Economics, Xi'an, China, ${ }^{3}$ Mineral Resource Strategy and Policy Research Center of China University of Geosciences, Wuhan, P. R. China 
quickly (Manyena 2006, Norris et al. 2008, Wagner and Breil 2013). Whereas UNISDR's (2009) definition of vulnerability is limited to the susceptibility to hazardous events, "the characteristics and circumstances of a community, system or asset that make it susceptible to the damaging effects of a hazard." Thus, vulnerability assessments focus more on the exposure of a social-ecological system (Yang et al. 2018), whereas resilience assessments focus more on the recovery and adaptability of the system (Cutter et al. 2008). Therefore, their evaluation index systems will contain different dimensions and indicators (e.g., Cutter et al. 2008, Hahn et al. 2009, Gautam 2017, Huong et al. 2019).

Despite the growing research on disaster resilience assessments, there is still considerable disagreement about what should constitute the disaster resilience index system. An authoritative and widely applicable disaster resilience evaluation system has not yet been developed (Saja et al. 2019). To get the main dimensions of the disaster resilience index, we summarized the elements that have been included in disaster resilience assessment (Fig. 2), referring to the following representative studies: Chang and Shinozuka 2004, Folke 2006, Mayunga 2007, Cutter et al. 2008, 2010, 2014, Razafindrabe et al. 2009, Cimellaro et al. 2016, and Kotzee and Reyers 2016. These studies provide useful references when constructing the disaster resilience index system. Economy, society, environment, and infrastructure have been most considered (Cutter 2016, Saja et al. 2019), thus our disaster resilience indicator system will include these four aspects. Along with some important attributes such as age, employment, education, and information access included in the resilience assessment, further analysis found that many factors such as expenditure, insurance, credit, social allowances, population growth, and redundancy of infrastructure were also considered. There are also numerous studies that include the environmental components in vulnerability assessments (Damm 2010, Renaud et al.2013, 2016). However, most of the existing studies on disaster resilience assessments focus on the social resilience to natural disasters, while the natural environmental resilience is often ignored (Saja et al. 2019). In fact, disaster impacts can also be reduced by improving the resilience of natural systems to disasters (Cutter et al. 2010). Some scholars such as Altieri et al. (2015) and Duncan et al. (2017) have proven that bad climate and weather will have a significant negative impact on disaster resilience. However, climate and weather factors are rarely included in these disaster resilience assessments (Cutter et al. 2008, Cimellaro et al. 2016, Kotzee and Reyers 2016). Therefore, the disaster resilience evaluation index system proposed we propose will take them into consideration.

There are different ways to measure composite indicators. Among them, the comprehensive index method, the principal component analysis, and the analytic hierarchy process are all used to quantify disaster resilience (Cutter et al. 2010, Yan et al. 2014, Kotzee and Reyers 2016). In addition, because of varying views on the importance of indicators (Meerow et al.2016), different weighting methods have been adopted, such as the average weight method (Cutter et al. 2014) and the Delphi method (Alshehri et al. 2015). However, because different methods have both advantages and limitations, it is difficult to determine which weighting or evaluation method is best suited to evaluate disaster resilience. Also, different evaluation methods are evaluated from different perspectives, thus the results of different methods may differ. For example, the SAW method focuses on the size of the index value, whereas the TOPSIS method focuses on the distance between the index value and the optimal value or the worst value. Some studies have proven that the combination method, which combines results of various evaluation methods by centralized sorting method, can improve the comprehensiveness and reliability of the conclusions (Guo 1995, Chen and Li 2004, Peng et al. 2016a). However, there is still a lack of research on disaster resilience assessment using the combination method (Rus et al. 2018). In addition, the current research on disaster resilience evaluation considers the selection of indicators, but ignores the influence that the change of weight may have on the evaluation results (Rus et al. 2018).

Fig. 2. Most common elements in disaster resilience index systems. Note: the higher the word frequency, the larger the word font.

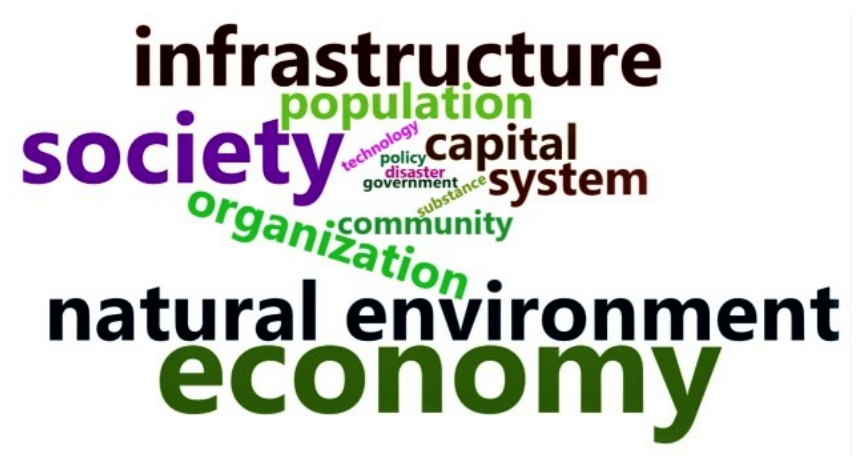

Based on the above considerations, our aim is to develop a disaster resilience evaluation index system from societal, economic, infrastructural, and natural environmental perspectives, and explore an integrated approach to produce an accurate evaluation of disaster resilience in the Three Gorges Reservoir Area. Based on the ranking, the Pearson correlation coefficient is used to calculate the correlation matrix for the disaster resilience and the four subsystems' resilience. At the same time, countermeasures for improving the disaster resilience are proposed to reduce disaster impacts, which improve adaptability and resilience in the Three Gorges Reservoir Area.

\section{BACKGROUND OF THE THREE GORGES RESERVOIR AREA IN CHINA}

The Three Gorges Reservoir Area in China, which is $54,200 \mathrm{~km}^{2}$, is located in the Chongqing and Hubei provinces (Fig. 3). The area is dominated by mountains and hills, with a mid-subtropical humid monsoon climate. The annual average temperature is $17^{\circ}$ $\mathrm{C} \sim 20^{\circ} \mathrm{C}$, and the average annual precipitation is $1000 \sim 1200$ $\mathrm{mm}$. The main hydro-meteorological disasters in the region are heavy rain, floods, high temperatures, and continuous rain. Its forest coverage rate is $49.08 \%$, mainly distributed in coniferous and broad-leaved forests, commercial fruit trees, and crops.

The agricultural production is mainly food crops. Arable land accounts for $40 \%$ of the land area. The average per capita is 0.005 ha, which is lower than the national average $(0.007$ ha; Peng et al. $2016 b$ ). Of the total population, $60 \%$ is engaged in agricultural work, although agricultural income accounts for only $19.8 \%$ of total revenue (Peng et al. 2016b). There are 26 counties in the Three Gorges Reservoir Area, of which 10 are state-level poverty 
counties. The poor are subsidized by the government for basic living expenses and a minimum living allowance. In addition, in the rural areas, there has been a new rural cooperative medical care system to ensure that farmers receive more adequate medical resources and services.

Fig. 3. Map of the Three Gorges Reservoir Area.

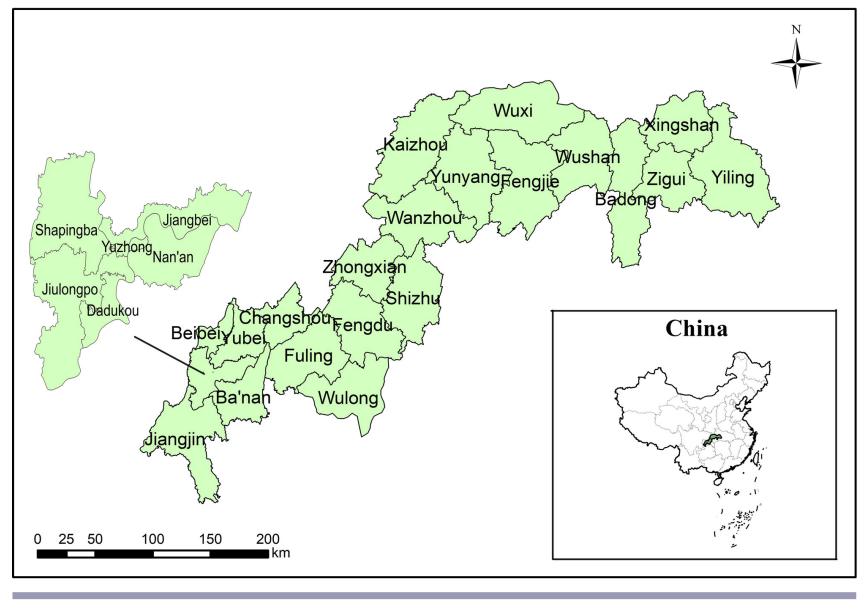

The Three Gorges Project is the largest water conservancy project in the Yangtze River Basin. The construction of the Three Gorges Dam has raised the water level to over 180 meters above sea level, inundated a large area of agricultural land, forest, house, and infrastructure, and displaced more than 1 million people in the Three Gorges Reservoir Area (Stone 2008, Kittinger et al. 2009). Notably, only $87.7 \%$ of farmers were resettled to areas where farming is possible, and per capita arable land was only a third of what it was before migration (Shi and Yang 2009). Reclaiming the land, constructing new infrastructure, and building new houses led to deforestation, causing serious soil erosion and increasing the risk of landslides and floods. Frequent heavy rain and the high reservoir water level also can increase the risk of landslide and flood. Dam-related seismicity also brings other natural hazards including earthquakes. In 2016, 481 earthquakes occurred in the Three Gorges Reservoir Area. A total of 4847 potential geological hazards were recorded in the Three Gorges Reservoir Area, of which 113 had structural changes and poorer stability in 2016 (MEP 2017).

Due to limitations of the terrain, many rural settlements are located in geological hazard threat areas, and some are even located in known disaster areas. Disasters such as landslides, collapses, and earthquakes often cause casualties, destroy houses, farmland, roads, telecommunications equipment, and so on, resulting in power outages, water cuts, shutdowns, and disruptions in transportation and communications. Many measures have been implemented to improve the region's ability to respond to disasters, involving risk investigation, education and training, migration, landslide monitoring, and engineering treatment (Liu et al. 2016).

\section{DATA AND METHODS}

Data sources

Although the Three Gorges Reservoir Area has 26 counties, only 17 counties were used as the research sample because of the lack of disaster data in 9 counties; Badong, Xingshan, Zigui, and Yiling are in the Hubei reservoir area, and other counties are in the Chongqing reservoir area. The landslide disaster index data were provided by the Geological Disaster Prevention and Control Headquarters in the Three Gorges Reservoir Area, which is responsible for the monitoring and analysis of geological disasters in the Three Gorges Reservoir Area, thus the authenticity and reliability of the data are guaranteed. Except for landslide disaster index data, the basic indicators data of economy, society, infrastructure, and environment selected in this research were extracted from the 2016 statistical bulletin of the national economy and social development of the counties, the statistical yearbooks of the respective counties in Chongqing, Yichang, and Enshi, the ecological and environmental monitoring bulletin of the Three Gorges Project of the Yangtze River, and the Chongqing water resources bulletin. Except for the landslide disaster data, the above data sets, compiled and published by the statistical bureau of the counties in the Three Gorges Reservoir Area, the statistical bureau of Chongqing, Yichang, and Enshi, Ministry of Environmental Protection of the People's Republic of China (now the Ministry of Ecology and Environment of the People's Republic of China), or Chongqing Water Resources Bureau, are available online. Links to these data sets can be found in Appendix 1. Some indicator data are calculated indirectly from the raw data. Table 1 lists the formula for calculating the indicator data.

Table 1. Indicator calculation formula.

\begin{tabular}{ll}
\hline \hline Basic Index Layer & Calculation Formula \\
\hline $\begin{array}{l}\text { Proportion of population } \\
\text { under 18 years old and over }\end{array}$ & $\begin{array}{l}\text { Proportion of population under 18 years } \\
\text { old + proportion of population over } 60 \\
\text { years old years old }\end{array}$ \\
$\begin{array}{l}\text { Government disaster relief } \\
\text { experience }\end{array}$ & $\begin{array}{l}\text { Number of government disaster relief } \\
\text { experiences from 2011 to 2016 } \\
\text { Energy efficiency }\end{array}$ \\
$\begin{array}{l}\text { Total industrial output/total industrial } \\
\text { energy consumption } \\
\text { (income of urban residents - income of }\end{array}$ \\
$\begin{array}{l}\text { disparity between urban and } \\
\text { rural areas }\end{array}$ & \begin{tabular}{l} 
rural residents)/income of all residents \\
\hline
\end{tabular}
\end{tabular}

\section{Measuring methods}

To resolve consistency problems of the weighting and evaluation methods, we employed a combined evaluation method that includes widely accepted weighting and evaluation methods (Jiang 2012), then used a centralized sorting method to combine and sort the evaluation results. The method proposed not only considered the influence of the different weights on the evaluation results but also considered the complementarity of the methods. For example, both the simple additive weighting (SAW) method and weighted product (WP) method are simple in their calculations, but more data from the original information are lost, whereas TOPSIS (technique for order of preference by similarity to ideal solution), VIKOR (VlseKriterijumska Optimizcija I Kaompromisno Resenje in Serbian), and other methods are more complicated, but they make full use of the original data information. By choosing the latter methods, we can effectively avoid any error caused by the disadvantages of the former evaluation methods. Therefore, we develop a disaster resilience evaluation index system for the Three Gorges Reservoir Area in China, then apply the developed comprehensive evaluation model 
Table 2. Abbreviations of the various methods.

\begin{tabular}{ll}
\hline \hline Methods & Abbreviations \\
\hline $\begin{array}{l}\text { Simple additive weighting } \\
\text { Technique for order preference by similarity to ideal } \\
\text { solution }\end{array}$ & SAW \\
$\begin{array}{l}\text { Vlsekriterijumska Optimizacija I Kompromisno Resenje } \\
\text { (in Serbian) }\end{array}$ & VIKOR \\
$\begin{array}{l}\text { Elimination and Et choice translating reality II } \\
\text { Preference ranking organization methods for enrichment } \\
\text { evaluations II }\end{array}$ & ELECTRE II \\
Peighted product & II \\
Root mean squared error of ranks & WP \\
Matching degree & RMSER \\
& MATCH $\%$ \\
\hline
\end{tabular}

to quantify the disaster resilience level in the area. The abbreviations of the methods we used are defined in Table 2.

The concept of resilience is not completely unified and the importance of indexes is not confirmed by the existing research (Meerow et al. 2016). In addition, the system of resilience indexing is not fully mature therefore researchers hold different views. Different weights of indicators may lead to inaccurate evaluation results; therefore, we use three common objective weighting methods: average weight method, gradual equal weight method, and entropy method. Average weight method is a method of assigning the same weight to each index. Under the gradual equal weight method, the weight of the subsystem is equal to 1 divided by the number of subsystems. The weight of the subclass is equal to the weight of the subsystem divided by the number of subclasses in the subclass layer. The weight of the basic index is equal to the weight of the subclass divided by the number of indicators of basic index layer. The gradual equal weight method can avoid the excessive weight difference among subsystems caused by the difference in the amount of basic index in each subclass layer. Entropy method provides the weights of the basic index based on data dispersion (Zou et al. 2006).

Multiattribute decision making, also known as multicriteria decision making (MCDM), is an important part of modern decision science. Its theories and methods have been widely applied in engineering, technology, economy, management, and other fields. Because the index weights have been calculated by the weighting methods, 6 evaluation methods applicable to the situation in which the index weight is known were adopted in this study to evaluate disaster resilience in 17 counties. These six methods are highly recognized in the field of MCDM (Jiang 2012). The SAW method is a MCDM method that is widely known and used (Hwang and Yoon 1981) and is suitable for evaluation problems characterized by simple calculation with low complexity. TOPSIS is one of the two existing MCDM methods for selecting compromise solutions (Hwang and Yoon 1981). By determining the shortest distance from the ideal (best) solution and the largest distance from the nadir (poorest) solution, TOPSIS evaluates alternatives. The WP method uses the weight of each attribute value (or indicator value) as the power of the corresponding attribute, so that the gap between the evaluation values of different alternatives becomes larger (Chang and Yeh 2001). The VIKOR method was developed from the compromise programming method, characterized by providing maximum group benefits and minimizing the number of the worst criterion. Therefore, the compromise solution can be accepted by the decision maker, and the compromise solution is the feasible solution, which is closest to the ideal solution of all solutions (Opricovic and Tzeng 2004). The PROMETHEE II (preference ranking organization methods for enrichment evaluations II) method is a multicriteria evaluation method put forward by Brans et al. (1986), which requires the criterion weight coefficient to be determined, with the decision maker defining or selecting an appropriate preference function for each criterion. The ELECTRE II (elimination and Et choice translating reality II) method builds a weak order relationship that does not require a transfer relationship between alternatives (Wang and Triantaphyllou 2008).

The outcome produced by the six ranking methods may not be consistent for a given index data and weight. In fact, the similarity and dissimilarity of the six methods should be examined to help select a more satisfying evaluation result (Liu et al. 2016). We use two validity coefficients to analyze the consistency and variety among six rank methods. Root-mean-square error is a method of calculating the dispersion of sample observations (Zanakis et al. 1998). The Match \% method refers to the ratio of the number of alternatives (or evaluated object) with the same ranking to the total number of alternatives, which the ranking results obtained using the two evaluation methods (Zanakis et al. 1998). These two methods are used to calculate the consistency between one evaluation method and the other evaluation methods.

The centralized sorting method adopts many evaluation methods, and then combines several evaluation results. It provides a way to solve the problem of consistency of evaluation methods (Tang and Zhang 2009). We used the mean value method, the Borda method, and the Copeland method to evaluate the ranking results. The mean value method reorders the evaluation objects according to the average value of the evaluation results (Tang and Zhang 2009). In the Borda and Copeland methods, the minority is subordinate to the majority. In the Borda method, the more times the evaluation object is superior to other evaluation objects, the better the evaluation object is (Tang and Zhang 2009). In the Copeland method, the more times the evaluation object is superior to other evaluation objects and the fewer times it is inferior to other evaluation objects, the better the evaluation object is (Tang and Zhang, 2009).

The calculation steps were as follows:

1. Min-max normalization was used to normalize the initial data matrix.

2. The average weight method (refers to the method of assigning the same weight to each index) was then employed to determine the weight of each index.

3. Based on the calculated weights, six evaluation methods (SAW, TOPSIS, VIKOR, EIECTRE II, PROMETHEE II, and WP) were then used to evaluate the disaster resilience of the counties in the Three Gorges Reservoir Area.

4. After determining the disaster resilience evaluation ranking, two similarity calculation methods, RMSER (root mean squared error of ranks) and MATCH $\%$ (matching degree) were used to eliminate incompatible evaluation results. More specifically, high RMSER and low MATCH\% indicated low compatibility. 
Fig. 4. Resilience evaluation method.

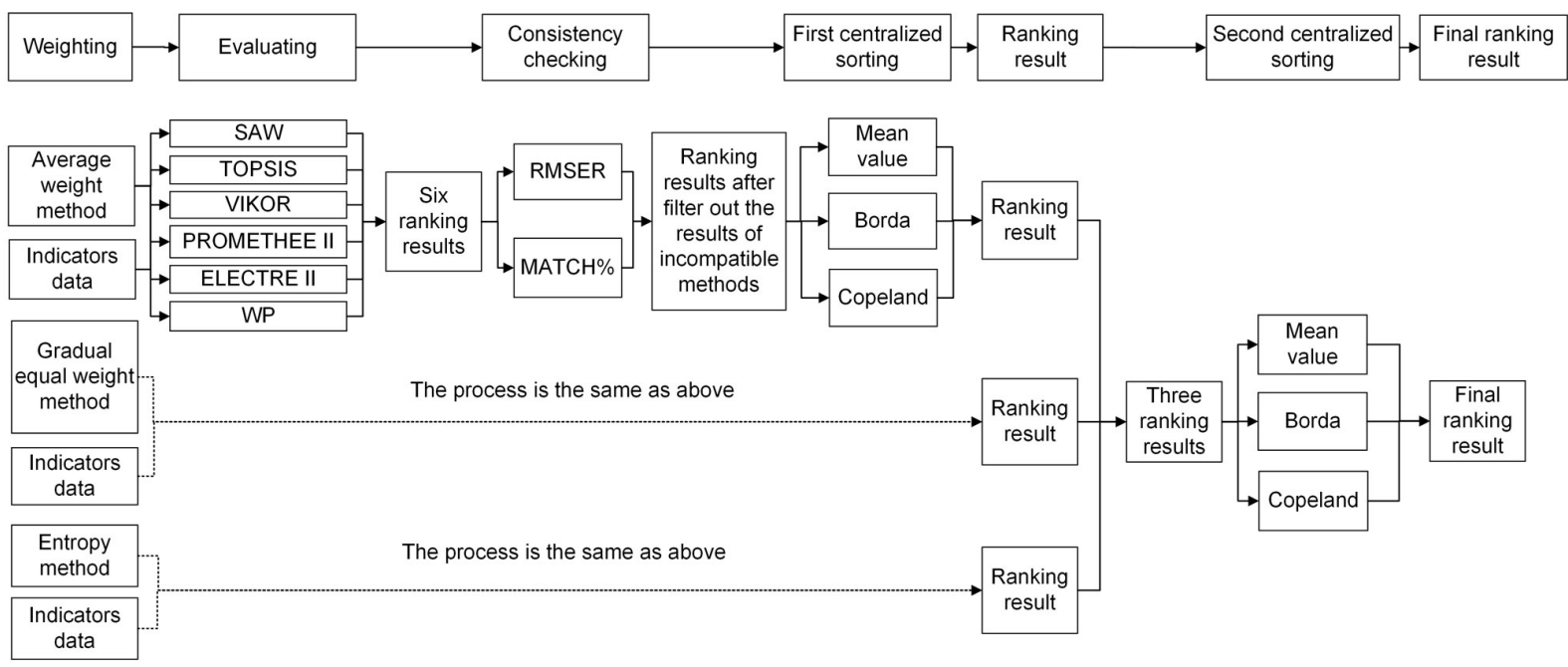

5. Three centralized sorting methods (the average method, the Borda method, and the Copeland method) were used to centralize the rankings for the compatible evaluation results.

6. The gradual equal weight method was then used to determine the weight of each index and steps of 3,4 , and 5 were repeated.

7. The entropy method was used to determine the weight of each index and steps of 3, 4, and 5 were repeated.

8. Three centralized sorting methods (the average method, the Borda method, and the Copeland method) were then used to centralize the three ranking results obtained in steps of 5,6 , and 7 , from which the final ranking results were determined.

The specific steps are outlined in Figure 4.

Because the weighting methods, evaluation methods, similarity calculation methods, and centralized sorting method we used are very mature and widely used, the detailed calculation steps of these methods can be found in previous research (Guo et al. 2009, Li and Wang 2012, Liu et al. 2016). After obtaining the disaster resilience and 4 subsystems resilience ranking of 17 counties, the Pearson correlation was used to calculate the correlation matrix.

\section{Establishment of the disaster resilience evaluation system}

Human and natural patterns and processes interact in cities and form an aggregation of ecological, infrastructure, social, and economic components. Because of the differences between countries and regions, local disaster resilience evaluation systems are required. Therefore, based on the preceding analysis and the summary of previous disaster resilience evaluation studies, the disaster resilience evaluation for the Three Gorges Reservoir Area was developed around four resilience dimensions: the natural environment, economy, infrastructure, and society. Economic resilience refers to the speed and quality of postdisaster urban recovery, focusing on economic diversity (or dependence on natural resources), employment, household assets, financial capacity, and government economic support to promote urban reconstruction and rehabilitation activities. Social resilience refers to the effectiveness of social action in disasters and is related to population attributes, social security, education, transportation, and other factors that affect community comprehension, communication, and mobility (Cutter et al. 2014). Infrastructure resilience is related to infrastructure redundancy and whether key facilities play a role in accessing critical resources, networks, or services such as electricity, tap water, networks, and transportation systems, as well as emergency services such as urban medical and early warning facilities in the aftermath of disasters. The natural environment provides the necessary materials and development spaces for the society, the economy, and the infrastructure, but at the same time, the natural environment is often related to the disaster environment; therefore, natural environment resilience can directly affect disaster resilience, and indirectly affect social, economic, and infrastructure resilience because of the specific ecological conditions, the type of disaster, and the local climate.

Therefore, infrastructural, economic, and social resilience were taken as the core dimensions for urban disaster resilience, and ecological resilience taken as the basic dimensions. The conceptual evaluation system framework is shown in Figure 5.

Fig. 5. Theoretical framework for measuring disaster resilience.

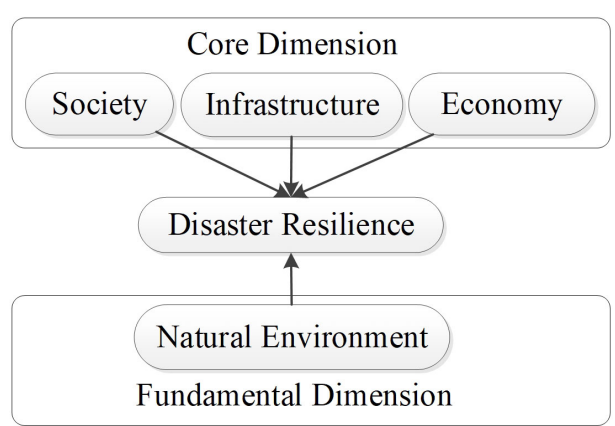


Table 3. Disaster resilience evaluation model.

\begin{tabular}{|c|c|c|c|c|}
\hline$\underline{\text { Destination layer }}$ & Subsystem layer & Subclass layer & Basic index layer & Effect on resilience \\
\hline \multirow[t]{42}{*}{ Resilience } & \multirow[t]{12}{*}{ Society } & \multirow[t]{3}{*}{ Population } & $\begin{array}{l}\text { Proportion of population under } 18 \text { years old and over } \\
60 \text { years old }\end{array}$ & Negative \\
\hline & & & Population density & Negative \\
\hline & & & Population growth rate & Negative \\
\hline & & \multirow[t]{6}{*}{ Social Security } & $\begin{array}{l}\text { Proportion of population with a minimum living } \\
\text { guarantee }\end{array}$ & Positive \\
\hline & & & Number of civic organizations per 10,000 population & Positive \\
\hline & & & Proportion of population with health insurance & Positive \\
\hline & & & Number of doctors per 10,000 population & Positive \\
\hline & & & $\begin{array}{l}\text { Main food production per capita (grain, vegetables, } \\
\text { fruit) }\end{array}$ & Positive \\
\hline & & & Government disaster relief experience & Positive \\
\hline & & \multirow[t]{2}{*}{ Education } & Number of public libraries per 10,000 population & Positive \\
\hline & & & Number of full-time teachers per 10,000 students & Positive \\
\hline & & Traffic & Vehicle ownership per 10,000 population & Positive \\
\hline & \multirow[t]{10}{*}{ Economy } & \multirow[t]{6}{*}{ Comprehensive Economy } & GDP per capita & Positive \\
\hline & & & Proportion of added value in primary industry & Negative \\
\hline & & & Unemployment rate & Negative \\
\hline & & & Proportion of nonagricultural population & Positive \\
\hline & & & Energy efficiency & Positive \\
\hline & & & Potential loss threatened by per unit volume landslide & Negative \\
\hline & & Government Finance & Local financial expenditure & Positive \\
\hline & & \multirow{3}{*}{ Individual Economy } & Savings per capita & Positive \\
\hline & & & Loans per capita & Positive \\
\hline & & & $\begin{array}{l}\text { Coefficient of income disparity between urban and } \\
\text { rural areas }\end{array}$ & Negative \\
\hline & \multirow[t]{12}{*}{ Infrastructure } & \multirow[t]{6}{*}{ Social Infrastructure } & Number of residential units per 10,000 population & Positive \\
\hline & & & Number of schools per 10,000 population & Positive \\
\hline & & & $\begin{array}{l}\text { Number of beds for social welfare adoption units per } \\
10,000 \text { population }\end{array}$ & Positive \\
\hline & & & Number of hospitals per 10,000 population & Positive \\
\hline & & & Number of beds in hospitals per 10,000 population & Positive \\
\hline & & & Housing area per capita & Positive \\
\hline & & \multirow[t]{6}{*}{ Economic Infrastructure } & Electricity consumption per capita & Negative \\
\hline & & & Water consumption per capita & Negative \\
\hline & & & Road length per capita & Positive \\
\hline & & & Highway density & Positive \\
\hline & & & Broadband Internet coverage & Positive \\
\hline & & & Number of mobile phones per 10,000 population & Positive \\
\hline & \multirow[t]{8}{*}{ Natural Environment } & Ecological Condition & Forest coverage & Positive \\
\hline & & \multirow{3}{*}{ Natural Disaster } & Degree of soil erosion (soil erosion modulus $t / \mathrm{km}^{2} / \mathrm{a}$ ) & Negative \\
\hline & & & Earthquake frequency & Negative \\
\hline & & & Distribution density of hidden landslide & Negative \\
\hline & & \multirow[t]{4}{*}{ Climate } & Days of high temperature & Negative \\
\hline & & & Rainstorm frequency & Negative \\
\hline & & & Days of continuous rain & Negative \\
\hline & & & Days of continuous strong cooling & Negative \\
\hline
\end{tabular}

These 4 dimensions were then further divided into 12 subclasses, each of which had several basic indexes. There were five considerations when selecting the basic indicators: (1) they needed to be based on previous research and be relevant to disaster resilience; (2) they must reflect the local geographical and regional characteristics; (3) they must be able to be converted into comparative forms; (4) they must be available from reliable data sources; and (5) a selective elimination of the relevant indicators was necessary if there was a high degree of correlation between the factors (Cutter et al. 2010, Zhou 2016). Therefore, based on these principles for index system construction and the data resources, initially, 63 indicators were collected for this study. Pearson's correlation coefficient was used to eliminate all the highly correlated variables (Pearson's $\mathrm{R}>0.70$ ), and 42 variables were retained as elements of the evaluation index system of disaster resilience (Table 3 ).

High social resilience means that a community can cope with the pressure of a disaster and have fewer negative societal consequences. We further subdivided the social resilience factors (population, social security, education, and traffic) into 12 subindicators. Linking population attributes with social resilience suggests that communities with a large proportion of young and middle-aged people, a low population growth rate, and low population density may be more resilient than communities without these characteristics (Borsekova et al. 2018). A greater concentration of doctors and health insurance enrollees indicates higher overall physical and mental health in the community. The 
number of vehicles indicates the ability to escape. Communities with higher education levels have a higher comprehensive quality in disaster response (Frankenberg et al. 2013). Experience with disaster relief and a good local food supply are also necessary qualities for preparing for, responding to, and recovering from disasters (Barthel et al. 2015).

Economic resilience is the capacity to reduce both direct and indirect disaster-related economic losses (Chang and Shinozuka 2004). Economic resilience is assessed from both macro and micro perspectives and includes consideration of the comprehensive economy, municipal finances, and the individual economy. Therefore, the indicators are related to the community's dependence on natural resources, its economic stability, and its compensation equality. Generally, gross domestic product (GDP) is used to indicate the overall size of the economy ( $\mathrm{Lu} 2018$ ), and if the impact of population size is excluded, GDP per capita can be used to reflect the overall economic characteristics; for example, a high GDP per capita and a low unemployment rate indicate a stable local economy. The energy efficiency reflects the impact of energy consumption on economic development. The potential losses per unit volume of a landslide can be used directly to evaluate economic resilience. In recent years, some studies on economic resilience have paid more attention to economic crises and regional industrial structural adjustments (Brown and Greenbaum 2017). As a traditional industry, primary industry depends on the available resources but can have a negative impact on the environment; therefore, the more enterprises that rely on natural resources, the slower the recovery rate. For the individual economy, families with higher average expenditures are more resilient to natural disasters, and access to microcredit, internal remittances, and social benefits can help families build resilience to natural disasters (Arouri et al. 2015, Kamal et al. 2018). The urban-rural income gap reflects the degree of balanced and coordinated development in the regional economy ( $\mathrm{Lu} 2018$ ), with unfair income distribution increasing the risk to vulnerable groups after a disaster.

Infrastructure as an indicator has been widely accepted by economists. The World Bank's 1994 World Development Report divided infrastructure into two categories: economic infrastructure; public utilities such as electricity, pipeline gas, water supply, sanitation facilities and sewerage systems, public works such as irrigation and roads, and other transport sectors such as railways, urban transport, seaports, waterways, and airports; and social infrastructure, which generally refers to business services, science, education, culture, health care, and related areas (World Bank 1994). The National Infrastructure Advisory Council (NIAC) defined infrastructure system resilience as the ability to predict, absorb, adapt, and quickly recover from a disruptive event, with the indicators being the number of residential units, schools, and hospitals per 10,000 people, and housing area per capita; all of which measure infrastructure soundness and ownership and estimate the capacity of a county to provide housing and emergency medical services for displaced people (NIAC 2009). Economic infrastructure variables, such as per capita road length, road density, Internet broadband coverage and mobile phones per 10,000 people, not only provide a means of communication for pre-event evacuations, but also serve as a conduit for vital postdisaster supplies (Cutter et al. 2010). The greater the per capita electricity consumption and water consumption of rural residents, the greater the inconvenience brought by the disaster.

The environment is generally divided into the human environment and the natural environment. Because of the overlap of the human environment and society and the economy and infrastructure, this research only involved the natural environment. Natural environmental resilience emphasizes the coordinated development of human and environmental systems. For example, the instability resulting from the climate and weather can affect the level and accessibility of food supplies, social and economic stability, and regional competitiveness (Altieri et al. 2015). The climate change risks are characterized by the frequency and intensity of extreme weather and climatic events that are caused by both human and natural conditions (Zhang and Li 2018). We selected eight indicators from three aspects; the ecological environment, disasters, and climate. Forest coverage indirectly affects natural environmental resilience by regulating the water, soil, biology, and climate. In the Three Gorges Reservoir Area, water and soil losses, earthquakes, and landslides are common natural disasters, with extreme weather events being common causes. Therefore, in areas with fewer water and soil losses, earthquakes and landslides, and good climate conditions, the possibility of disaster is low.

\section{RESULTS AND ANALYSIS}

\section{Ranking results}

In the case of average weight method, the results of the six evaluation methods are shown in Table 4. According to scores calculated by the SAW and TOPSIS methods, we can conclude that the disaster resilience of the counties in the Three Gorges Reservoir Area are relatively low.

Table 4. Disaster resilience ranking calculated using the average weight method.

\begin{tabular}{|c|c|c|c|c|c|c|c|c|c|c|}
\hline ounties & $\begin{array}{l}\text { Score } \\
\text { for } S\end{array}$ & $\mathrm{~S}$ & $\begin{array}{l}\text { Score } \\
\text { for } \mathrm{T}\end{array}$ & $\mathrm{T}$ & $\begin{array}{l}\text { Score } \\
\text { for W }\end{array}$ & W & $\begin{array}{l}\text { Score } \\
\text { for P }\end{array}$ & $\mathrm{P}$ & V & E \\
\hline & 532 & 3 & 0.521 & 3 & 0.843 & 16 & 0.039 & 7 & 3 & 6 \\
\hline & & & & & & 9 & & & & \\
\hline gshou & 0 & 11 & & 11 & & 1 & & 12 & 11 & 15 \\
\hline & & 10 & & 10 & & 14 & & 8 & 10 & 10 \\
\hline & & 8 & & & & 5 & & 9 & 8 & \\
\hline & & 15 & & 15 & & 12 & & 15 & 15 & 16 \\
\hline & & 16 & & 16 & & 15 & & 16 & 16 & 14 \\
\hline & & 12 & & 12 & & 6 & & 14 & 12 & 11 \\
\hline & & 9 & & 9 & & 4 & & 10 & 9 & 8 \\
\hline Wus & & 13 & 0.451 & 13 & & 10 & -0.062 & 11 & 13 & 13 \\
\hline & & 4 & & 5 & & 11 & & 5 & 4 & 5 \\
\hline & & 1 & & 1 & & 2 & & 1 & & \\
\hline & & 6 & & 6 & & 3 & & 4 & & \\
\hline & & 2 & & 2 & & 7 & & 2 & 2 & 2 \\
\hline Xingsh & & 5 & & 4 & & 8 & & 3 & 5 & 3 \\
\hline Zigui & & 14 & & 14 & & 17 & -0.071 & 13 & 14 & \\
\hline Badong & 0.383 & 17 & 0.416 & 17 & 0.899 & 13 & -0.181 & 17 & 17 & 17 \\
\hline
\end{tabular}

Note: $\mathrm{S}=\mathrm{SAW}, \mathrm{T}=$ TOPSIS, $\mathrm{W}=\mathrm{WP}, \mathrm{V}=$ VIKOR, $\mathrm{P}=$ PROMETHEE

II, E = ELECTRE II. SAW, TOPSIS, WP, and PROMETHEE II all had

a final score, and the rank is followed by the final score.

In addition, we can see that there are some differences in the ranking results of different methods. Further, there is a great difference between the ranking results of the WP method and the other five methods, indicating that WP has the highest RMSER 
and the lowest $\mathrm{MATCH} \%$ compared with the other methods; therefore, as WP has the lowest compatibility, the results calculated by WP were eliminated. Based on the results of the gradual equal-weight method and the entropy method, similar conclusions can be drawn, as shown in Tables 5 and 6 .

Table 5. Disaster resilience ranking calculated using the gradual equal weight method.

\begin{tabular}{lccccccccccc}
\hline \hline Counties & $\begin{array}{c}\text { Score } \\
\text { of S }\end{array}$ & S & $\begin{array}{c}\text { Score } \\
\text { of T }\end{array}$ & $\begin{array}{c}\text { T } \\
\text { Score of } \\
\text { W }\end{array}$ & $\begin{array}{c}\text { W } \\
\text { Score } \\
\text { of P }\end{array}$ & P & V & E \\
\hline Dadukou & 0.506 & 5 & 0.441 & 6 & 0.839 & 16 & 0.038 & 7 & 6 & 7 \\
Fuling & 0.471 & 7 & 0.432 & 8 & 0.933 & 9 & 0.073 & 6 & 7 & 6 \\
Changshou & 0.432 & 9 & 0.398 & 10 & 0.970 & 1 & -0.029 & 8 & 12 & 9 \\
Wanzhou & 0.389 & 14 & 0.339 & 16 & 0.884 & 14 & -0.100 & 13 & 17 & 14 \\
Fengdu & 0.422 & 11 & 0.368 & 13 & 0.951 & 5 & -0.074 & 12 & 13 & 13 \\
Zhongxian & 0.382 & 15 & 0.352 & 14 & 0.902 & 12 & -0.130 & 15 & 15 & 15 \\
Kaizhou & 0.395 & 13 & 0.381 & 12 & 0.881 & 15 & -0.101 & 14 & 11 & 12 \\
Yunyang & 0.421 & 12 & 0.413 & 9 & 0.949 & 6 & -0.058 & 10 & 8 & 8 \\
Fengjie & 0.427 & 10 & 0.396 & 11 & 0.952 & 4 & -0.061 & 11 & 10 & 10 \\
Wushan & 0.433 & 8 & 0.435 & 7 & 0.927 & 10 & -0.045 & 9 & 9 & 11 \\
Wuxi & 0.586 & 1 & 0.611 & 1 & 0.908 & 11 & 0.203 & 3 & 1 & 4 \\
Wulong & 0.585 & 2 & 0.556 & 3 & 0.958 & 2 & 0.212 & 1 & 5 & 2 \\
Shizhu & 0.565 & 3 & 0.588 & 2 & 0.957 & 3 & 0.204 & 2 & 2 & 1 \\
Yiling & 0.522 & 4 & 0.487 & 4 & 0.935 & 7 & 0.175 & 4 & 3 & 3 \\
Xingshan & 0.505 & 6 & 0.482 & 5 & 0.934 & 8 & 0.109 & 5 & 4 & 5 \\
Zigui & 0.371 & 16 & 0.341 & 15 & 0.831 & 17 & -0.157 & 16 & 14 & 16 \\
Badong & 0.332 & 17 & 0.311 & 17 & 0.895 & 13 & -0.251 & 17 & 16 & 17 \\
\hline Nite: S SAW T & & & & & & &
\end{tabular}

Note: $\mathrm{S}=\mathrm{SAW}, \mathrm{T}=$ TOPSIS, $\mathrm{W}=\mathrm{WP}, \mathrm{V}=$ VIKOR, $\mathrm{P}=$ PROMETHEE II, E = ELECTRE II. SAW, TOPSIS, WP, and PROMETHEE II all had a final score, and the rank is followed by the final score.

Table 6. Disaster resilience ranking calculated using the entropy method.

\begin{tabular}{lccccccccccc}
\hline \hline Counties & $\begin{array}{c}\text { Score } \\
\text { of S }\end{array}$ & S & $\begin{array}{c}\text { Score } \\
\text { of T }\end{array}$ & $\begin{array}{c}\text { T } \\
\text { Dcore of } \\
\text { W }\end{array}$ & $\begin{array}{c}\text { W } \\
\text { Score } \\
\text { of P }\end{array}$ & P & V & E \\
\hline Dadukou & 0.530 & 4 & 0.518 & 6 & 0.843 & 16 & 0.0305 & 7 & 9 & 7 \\
Fuling & 0.493 & 7 & 0.496 & 7 & 0.933 & 9 & 0.0677 & 6 & 10 & 6 \\
Changshou & 0.443 & 11 & 0.462 & 11 & 0.970 & 1 & -0.064 & 12 & 11 & 15 \\
Wanzhou & 0.447 & 10 & 0.463 & 10 & 0.885 & 14 & -0.019 & 9 & 14 & 10 \\
Fengdu & 0.471 & 8 & 0.483 & 8 & 0.950 & 5 & -0.017 & 8 & 5 & 9 \\
Zhongxian & 0.418 & 15 & 0.446 & 15 & 0.904 & 12 & -0.097 & 15 & 16 & 16 \\
Kaizhou & 0.415 & 16 & 0.444 & 16 & 0.881 & 15 & -0.111 & 16 & 12 & 14 \\
Yunyang & 0.441 & 12 & 0.461 & 12 & 0.949 & 6 & -0.083 & 14 & 13 & 11 \\
Fengjie & 0.459 & 9 & 0.473 & 9 & 0.953 & 4 & -0.052 & 10 & 2 & 8 \\
Wushan & 0.440 & 13 & 0.459 & 13 & 0.928 & 10 & -0.059 & 11 & 7 & 12 \\
Wuxi & 0.534 & 3 & 0.526 & 3 & 0.907 & 11 & 0.098 & 4 & 3 & 5 \\
Wulong & 0.576 & 1 & 0.557 & 1 & 0.959 & 2 & 0.199 & 1 & 1 & 1 \\
Shizhu & 0.529 & 5 & 0.523 & 4 & 0.955 & 3 & 0.097 & 5 & 4 & 4 \\
Yiling & 0.545 & 2 & 0.533 & 2 & 0.935 & 7 & 0.152 & 2 & 6 & 2 \\
Xingshan & 0.528 & 6 & 0.521 & 5 & 0.934 & 8 & 0.113 & 3 & 8 & 3 \\
Zigui & 0.419 & 14 & 0.448 & 14 & 0.836 & 17 & -0.072 & 13 & 15 & 13 \\
Badong & 0.387 & 17 & 0.422 & 17 & 0.899 & 13 & -0.181 & 17 & 17 & 17 \\
\hline
\end{tabular}

Note: $\mathrm{S}=\mathrm{SAW}, \mathrm{T}=$ TOPSIS, $\mathrm{W}=\mathrm{WP}, \mathrm{V}=\mathrm{VIKOR}, \mathrm{P}=$ PROMETHEE II, E = ELECTRE II. SAW, TOPSIS, WP, and PROMETHEE II all had a final score, and the rank is followed by the final score.

The mean value, Borda, and Copelands method were used to synthesize the ranking results in Table 4, 5, and 6, and the results are shown in Table 7 . Then, these three ranking methods were used to synthesize the ranking results in Table 7, from which Table 8 was obtained. It can be seen that the evaluation results are gradually consistent after two centralized sortings. Finally, the final disaster resilience ranking for the 17 counties in the Three Gorges Reservoir Area was obtained (Fig. 6; Table 9) based on the results in Table 8 .

Table 7. Results from the first centralized sorting.

\begin{tabular}{lccc}
\hline \hline Counties & Rank of A & Rank of G & Rank of E \\
\hline Dadukou & 3 & 6 & 3 \\
Fuling & 7 & 7 & 7 \\
Changshou & 11 & 10 & 11 \\
Wanzhou & 10 & 14 & 10 \\
Fengdu & 8 & 13 & 8 \\
Zhongxian & 15 & 15 & 15 \\
Kaizhou & 16 & 12 & 16 \\
Yunyang & 12 & 9 & 12 \\
Fengjie & 9 & 11 & 9 \\
Wushan & 13 & 8 & 13 \\
Wuxi & 5 & 1 & 5 \\
Wulong & 1 & 3 & 1 \\
Shizhu & 6 & 2 & 6 \\
Yiling & 2 & 4 & 2 \\
Xingshan & 4 & 5 & 4 \\
Zigui & 14 & 16 & 14 \\
Badong & 17 & 17 & 17
\end{tabular}

Note: In Table 7, A = average weight method, $\mathrm{G}=$ gradual equal weight method, $\mathrm{E}=$ entropy method.

Table 8. Results using the second centralized sorting.

\begin{tabular}{lccc}
\hline \hline Counties & Result of $\mathrm{M}$ & Result of B & Result of C \\
\hline Dadukou & 4 & 3 & 3 \\
Fuling & 7 & 7 & 7 \\
Changshou & 10 & 10 & 10 \\
Wanzhou & 12 & 12 & 12 \\
Fengdu & 8 & 8 & 8 \\
Zhongxian & 16 & 16 & 16 \\
Kaizhou & 14 & 15 & 15 \\
Yunyang & 11 & 11 & 11 \\
Fengjie & 8 & 9 & 9 \\
Wushan & 12 & 13 & 13 \\
Wuxi & 3 & 4 & 4 \\
Wulong & 1 & 1 & 1 \\
Shizhu & 6 & 6 & 6 \\
Yiling & 2 & 2 & 2 \\
Xingshan & 5 & 5 & 5 \\
Zigui & 14 & 14 & 14 \\
Badong & 17 & 17 & 17
\end{tabular}

Note: In Table $8, \mathrm{M}=$ the mean value method, $\mathrm{B}=$ Borda method, and $\mathrm{C}$ $=$ Copeland method.

According to the methods we used, the resilience of four subsystems can also get a final ranking, as shown in Figure 7.

\section{Analysis of the ranking results}

From the ranking results, the disaster resilience intensity was divided into three grades according to the final ranking: counties ranked 1-6 were the high resilience areas, 7-12 were the medium resilience areas, and 13-17 were the low resilience areas. Table 10 gives a detailed analysis of these three disaster resilience levels in the Three Gorges Reservoir Area. 
Fig. 6. Disaster resilience ranking in the Three Gorges Reservoir Area.

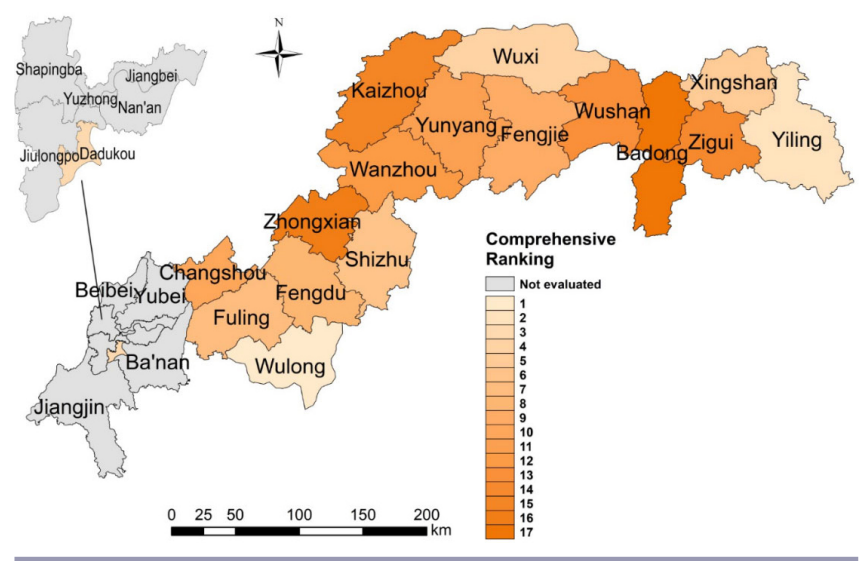

Table 9. Final results.

\begin{tabular}{lclc}
\hline \hline Counties & $\begin{array}{c}\text { Final } \\
\text { ranking }\end{array}$ & Counties & Final ranking \\
\hline Dadukou & 3 & Wushan & 13 \\
Fuling & 7 & Wuxi & 4 \\
Changshou & 10 & Wulong & 1 \\
Wanzhou & 12 & Shizhu & 6 \\
Fengdu & 8 & Yiling & 2 \\
Zhongxian & 16 & Xingshan & 5 \\
Kaizhou & 15 & Zigui & 14 \\
Yunyang & 11 & Badong & 17 \\
Fengjie & 9 & & \\
\hline
\end{tabular}

Fig. 7. Disaster resilience ranking for the four subsystems in the Three Gorges Reservoir Area.

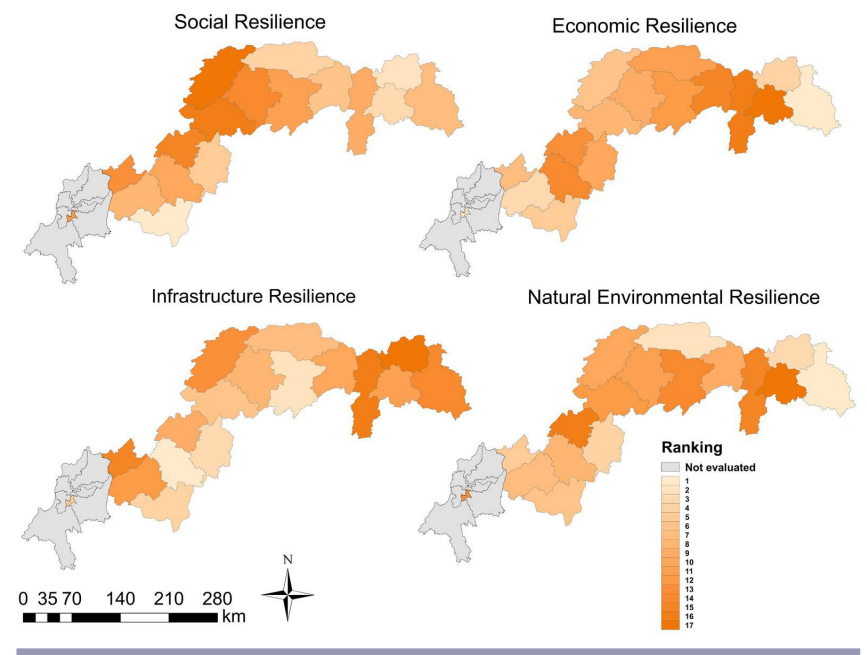

As can be seen from Figures 6 and 7, the disaster resilience and four subsystems resilience in the Three Gorges Reservoir Area has distinct geographical differences.
- On the whole, the disaster resilience gradually decreases from the Chongqing reservoir area to the Hubei reservoir area. Specifically, the disaster resilience of the ZhongxianZigui section (except for Wuxi) was low, mainly because of the low economic, environmental, and social resilience. The reason why the other counties have high disaster resilience was that all four subsystems were found to be more resilient. Therefore, it is necessary to improve the comprehensive disaster resilience in the Three Gorges Reservoir Area by implementing measures in the areas of low subsystem resilience, especially in the Zhongxian-Zigui section.

- The social resilience in the Zhongxian-Fengjie section, Dadukou, and the Changshou area were all found to be low because the population, social security, and traffic resilience were low. Therefore, these counties urgently need to improve the population and social security resilience by, for example, reducing the natural population growth rate and reducing the population density. The government needs to strengthen the minimum living security of the urban residents, increase the proportion of the population with health insurance, and guarantee the farming areas to ensure food security. Other counties were found to have relatively high social resilience because of their high population, social security, education, and traffic resilience.

- The Fengdu-Zigui section was found to have low economic resilience because the government's financial and personal economic resilience were low. The main characteristics of low economic resilience are low GDP per capita, high value added in the primary industry, a small agricultural population proportion, and a large income gap between the urban and rural areas. To promote resilience, the industrial structure needs to be optimized, and the integration of the primary industry into the secondary and service industrial chains needs to be sped up to promote industrial structure rationalization in the Three Gorges Reservoir Area. The reason for the higher economic resilience of other counties was the high resilience in comprehensive economy, government finance, and individual economy. For counties that have strong economic bases (Yiling, Xingshan, Dadukou, etc.), strategic emerging industries and high-tech industries such as the Internet of Things, robotics technology, high-end equipment manufacturing, new energy vehicles can be developed and transportation network systems can be promoted and strengthened to develop modern logistics industry (Huang et al. 2015).

- The infrastructure resilience in the Chongqing reservoir area was found to be relatively high but relatively low in the Hubei reservoir area, which was primarily because the economic infrastructure resilience in the Hubei reservoir area was low; therefore, the government needs to increase financial subsidies to improve the infrastructure in this area.

- The geographic distribution of environmental resilience and comprehensive disaster resilience were found to be similar, which indicated that the environmental resilience had the greatest influence on the comprehensive resilience. Specifically, the environmental resilience in the ZhongxianZigui section (except for Wuxi) was found to be relatively low, primarily because of the low ecological and disaster 
Table 10. Disaster resilience analysis of the 17 counties in the Three Gorges Reservoir Area.

\begin{tabular}{|c|c|c|}
\hline Classification & County & Specific analysis \\
\hline High resilience areas & $\begin{array}{l}\text { Wulong, Yiling, } \\
\text { Dadukou, Wuxi, } \\
\text { Xingshan, Shizhu }\end{array}$ & $\begin{array}{l}\text { The four subsystems in these six counties had relatively high recovery capacities. However, except for } \\
\text { Wulong, each county had weaknesses; the infrastructure resilience in Yiling and Xingshan, the social } \\
\text { resilience and natural environment resilience in Dadukou, and the economic resilience in Wuxi were all } \\
\text { below the medium level. Further analysis showed that there were low traffic resilience in Dadukou and } \\
\text { Xingshan, low individual economic resilience in Wuxi, and low population resilience, climate resilience, } \\
\text { and ecological resilience in Dadukou. }\end{array}$ \\
\hline $\begin{array}{l}\text { Medium resilience } \\
\text { areas }\end{array}$ & $\begin{array}{l}\text { Fuling, Fengdu, } \\
\text { Fengjie, Changshou, } \\
\text { Yunyang, Wanzhou }\end{array}$ & $\begin{array}{l}\text { These six counties had relatively high infrastructure recovery capacities, with Fengdu, Fengjie, and } \\
\text { Wanzhou ranking quite high; however, the economic infrastructure resilience in Changshou was very low. } \\
\text { The social resilience was generally at a medium level, but the education resilience in Wanzhou, the social } \\
\text { security resilience in Changshou, and the population resilience in Fengdu were all low. The main reason for } \\
\text { the low economic resilience was that the government's fiscal resilience was weak, and Fengdu was ranked } \\
\text { as backward mainly because of its weak comprehensive economic capacity, government financial capacity, } \\
\text { and personal economic capacity. Although Yunyang and Fengjie had medium comprehensive economic } \\
\text { resilience, their individual economic resilience needs urgent improvements. The ecological and disaster } \\
\text { resilience in these six counties were poor, especially in Wanzhou and Fengdu. Disasters in Yunyang and } \\
\text { Fengjie are more threatening. On the whole, these six counties were at a medium level. }\end{array}$ \\
\hline Low resilience areas & $\begin{array}{l}\text { Wushan, Zigui, } \\
\text { Kaizhou, Zhongxian, } \\
\text { Badong }\end{array}$ & $\begin{array}{l}\text { The resilience of the four subsystems in these five counties was poor. For example, although Wushan, } \\
\text { Zigui, and Badong had relatively strong social resilience, the resilience of the other subsystems and } \\
\text { especially economic resilience was weak. Although Kaizhou ranked high in economic resilience, its } \\
\text { government finance and individual economic resilience were poor, and its social resilience ranked the } \\
\text { lowest. Although the infrastructure resilience in Zhongxian was at a medium level, the resilience of the } \\
\text { other three subsystems was poor, especially population resilience, social security resilience, and traffic } \\
\text { resilience in the society subsystem, government finance in the economy subsystem, and climate resilience in } \\
\text { the natural environment subsystem. }\end{array}$ \\
\hline
\end{tabular}

resilience; however, Wuxi and the other counties had higher environmental resilience because their ecological conditions and climate resilience were relatively high and the disaster threat relatively low. Because disaster occurrences are often related to ecological conditions, and the lower part of the mountain bodies on both sides of the Three Gorges have been immersed for a long time, the overall environmental system has become relatively fragile, which means that there is a risk that the disaster frequency will increase. Therefore, the most important task is to improve the ecological environment.

Overall, the disaster resilience level in the Three Gorges Reservoir Area was found to be relatively low, primarily because of the low resilience of the society, economy, infrastructure, and natural environment. Low ecological environment resilience was found in the Three Gorges Reservoir Area because of the unstable climate conditions, the high disaster frequency, the large hidden landslide dangers, the serious soil erosion, and the low vegetation cover. The infrastructure resilience was also low because of the harsh natural environment, which made infrastructure construction difficult. Because of the low infrastructure resilience, the economic losses, and threats to life suffered from various disasters, and the somewhat backward social and economic development in the Three Gorges Reservoir Area, the economic and social resilience were also relatively low.

\section{Relationship between the disaster resilience and the resilience in the four subsystems}

Figure 8 shows the correlations between disaster resilience and the resilience in the four subsystems. (1) There was a moderate correlation between the comprehensive resilience and the natural environment resilience, economic resilience, and social resilience, respectively, while a stronger relationship was found between the
Fig. 8. Correlation matrix for the disaster resilience and the four subsystems' resilience. Note: $\mathrm{SR}=$ social resilience, $\mathrm{ER}=$ economic resilience, $\mathrm{IR}=$ infrastructure resilience, $\mathrm{NER}=$ natural environment resilience, $\mathrm{DR}=$ disaster resilience; the correlation matrix was calculated using Pearson's correlation; $r$ $>0$ indicated a positive correlation between the two variables; $r$ $<0$ indicated a negative correlation of the two variables; $|\mathrm{r}| \geq$ 0.8 indicated that the two variables were highly correlated; $0.5 \leq$ $|\mathrm{r}|<0.8$ indicated that the two variables were moderately correlated; $0.3 \leq|\mathrm{r}|<0.5$ indicated that two variables had a low correlation; and $|\mathrm{r}|<0.3$ indicated that the correlation between the two variables was weak and basically irrelevant.

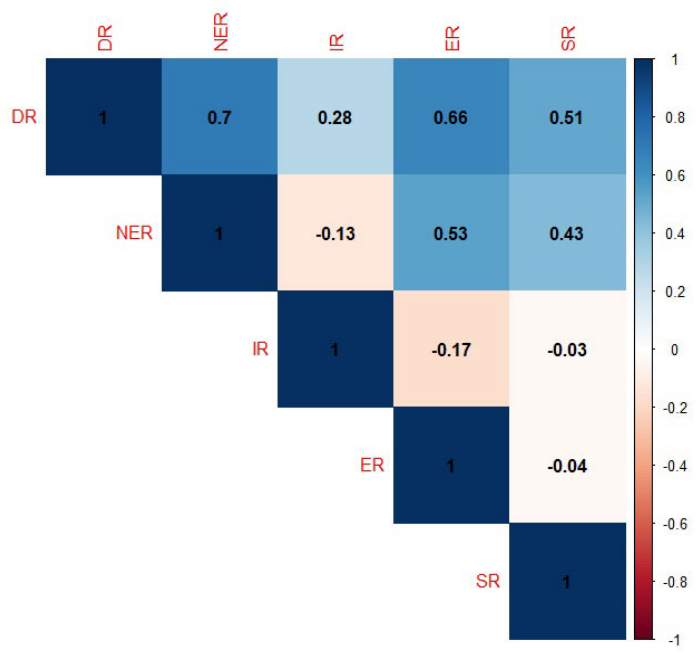


natural environment resilience and economic resilience; that is, as the correlation between infrastructure resilience and comprehensive disaster resilience was basically irrelevant, it could be inferred that improvements in natural environment resilience, economic resilience, and social resilience would lead to higher improvements in the comprehensive resilience.

(2) The correlation analysis between the four subsystems showed that the natural environment resilience was only moderately correlated with economic resilience, which could be due to the impact of the harsh natural environment on economic resilience. The natural environment resilience was also found to have a low correlation with social resilience, indicating that there may be high social resilience but low natural environment resilience. Basically, no correlation was found between the natural environment and infrastructure resilience, infrastructure and economic resilience, infrastructure and social resilience, and economic and social resilience. Some studies have found the natural environment affected infrastructure construction, that economic and social development interacted, and infrastructure construction could affect social development. The results of this study found that the resilience correlations between four subsystems were weak, which indicated that even though there was some influence between every two subsystems, there was not a strong correlation between the resilience in every two subsystems. Therefore, the key to improving the comprehensive disaster resilience in the Three Gorges Reservoir Area is to enhance the ecological environmental resilience.

\section{CONCLUSIONS}

This study provides an integrated methodology and a set of indicators to measure disaster resilience, which can help obtain objective and consistent evaluation results. Governments can compare the resilience of different districts and counties to know their relative resilience and whether they need to learn from more resilient districts and counties to determine emergency responses, recovery, and mitigation in critical circumstances. Based on a fourlevel hierarchical indicator system, we evaluated the disaster resilience in 17 counties in the Three Gorges Reservoir Area by combining six evaluation methods and three weighting methods. The ranking results of six evaluation methods were different, particularly with the WP method. After removing the ranking result of WP, the final ranking results were obtained by the mean value, Borda, and Copeland methods.

According to the evaluation results of 17 districts and counties, the overall disaster resilience level of the Three Gorges Reservoir Area was found to be low. This indicates the necessity of having resilience management plans in the Three Gorges Reservoir Area, particularly for the counties with poorer resilience to natural disasters such as Wushan, Zigui, Kaizhou, Zhongxian, and Badong. In terms of geographical distribution, the disaster resilience was found to gradually decrease from the Chongqing reservoir area to that in Hubei. The geographical distribution of the environmental resilience was similar to that of the comprehensive resilience. The environmental resilience in the Zhongxian-Zigui section (except Wuxi) was low. Infrastructure resilience in the Hubei reservoir area was lower than that in the Chongqing reservoir area. The social resilience in the ZhongxianFengjie section, Dadukou, and Changshou reservoir area was low, and the economic resilience in the Fengdu-Zigui section was low.
Therefore, corresponding measures should be taken to promote the resilience of subsystems so as to enhance the overall disaster resilience. The natural environment resilience was found to be mostly related to the comprehensive disaster resilience. Within the four subsystems, economic resilience was moderately related to the natural environment resilience. This suggests that improving the natural environmental resilience is an important way to enhance the disaster resilience. As a result, the government should pay more attention to the improvement of the resilience of the natural environment.

This study is expected to provide a more reasonable basis for policymakers to make more effective use of scarce resources and maximize their role, rather than distribute resources equally in all counties of the Three Gorges Reservoir Area. Because the resilience was examined from a static perspective in this study, quantifying the resilience changes in the studied area should be considered in future studies.

Responses to this article can be read online at: http://www.ecologyandsociety.org/issues/responses. php/11464

\section{Acknowledgments:}

This research is supported by the National Natural Science Foundation of China under Grants No. 71573237 and 71874165; the New Century Excellent Talents in the University of China under Grant No. NCET-13-1012; the Research Foundation of Humanities and Social Sciences of Ministry of Education of China No.15YJA630019; the China Institute of Geo-Environment Monitoring No. 0001212016CC60013; the Natural Science Foundation of Hubei Province of China No. 2016CFB503; Open Foundation for the Research Center of Resource Environment Economics in China University of Geosciences (Wuhan) under Grant No. H2017003A and H2018008A; Open Foundation for Hubei Provincial Ecological Civilization Research Center in China University of Geosciences (Wuhan) under Grant No. STZK2018z09; and the Fundamental Research Founds for National University, China University of Geosciences(Wuhan) No.1910491T10.

\section{Data Availability Statement:}

The data that support the findings of this study are available on request from the corresponding author, Haixiang Guo. The data are not publicly available because some of the information involves national privacy. Code sharing is not applicable to this article because no new code was created.

\section{LITERATURE CITED}

AghaKouchak, A., L. S. Huning, F. Chiang, M. Sadegh, F. Vahedifard, O. Mazdiyasni, H. Moftakhari, and I. Mallakpour. 2018. How do natural hazards cascade to cause disasters? Nature 561(7724):458-460. https://doi.org/10.1038/d41586-018-06783-6

Aitsi-Selmi, A., S. Egawa, H. Sasaki, C. Wannous, and V. Murray. 2015. The Sendai framework for disaster risk reduction: renewing 
the global commitment to people's resilience, health, and wellbeing. International Journal of Disaster Risk Science 6(2):164-176. https://doi.org/10.1007/s13753-015-0050-9

Aldrich, D. P. 2012. Building resilience: social capital in postdisaster recovery. University of Chicago Press, Chicago, USA. https://doi.org/10.7208/chicago/9780226012896.001.0001

Alshehri, S. A., R. Yacine, and H. Li. 2015. Disaster community resilience assessment method: a consensus-based Delphi and AHP approach. Natural Hazards 78(1):395-416. https://doi. org/10.1007/s11069-015-1719-5

Altieri, M. A., C. I. Nicholls, A. Henao, and M. A. Lana. 2015. Agroecology and the design of climate change-resilient farming systems. Agronomy for Sustainable Development 35(3):869-890. https://doi.org/10.1007/s13593-015-0285-2

Arouri, M., C. Nguyen, and A. B. Youssef. 2015. Natural disasters, household welfare, and resilience: evidence from rural Vietnam. World Development 70:59-77. https://doi.org/10.1016/j. worlddev.2014.12.017

Bai, S.-B., J. Wang, G.-N. Lü, P.-G. Zhou, S.-S. Hou, and S.-N. $\mathrm{Xu}$. 2010. GIS-based logistic regression for landslide susceptibility mapping of the Zhongxian segment in the Three Gorges Area, China. Geomorphology 115(1-2):23-31. https://doi. org/10.1016/j.geomorph.2009.09.025

Barthel, S., J. Parker, and H. Ernstson. 2015. Food and green space in cities: a resilience lens on gardens and urban environmental movements. Urban Studies 52(7):1321-1338. https://doi.org/10.1177/0042098012472744

Birkmann, J., O. D. Cardona, M. L. Carreño, A. H. Barbat, M. Pelling, S. Schneiderbauer, S. Kienberger, M. Keiler, D. Alexander, P. Zeil, and T. Welle. 2013. Framing vulnerability, risk and societal responses: the MOVE framework. Natural Hazards 67(2):193-211. https://doi.org/10.1007/s11069-013-0558-5

Borsekova, K., P. Nijkamp, and P. Guevara. 2018. Urban resilience patterns after an external shock: an exploratory study. International Journal of Disaster Risk Reduction 31:381-392. https://doi.org/10.1016/j.ijdrr.2018.05.012

Brans, J. P., Ph. Vincke, and B. Mareschal. 1986. How to select and how to rank projects: the PROMETHEE method. European Journal of Operational Research 24(2):228-238. https://doi. org/10.1016/0377-2217(86)90044-5

Brown, L., and R. T. Greenbaum. 2017. The role of industrial diversity in economic resilience: an empirical examination across 35 years. Urban Studies 54(6):1347-1366. https://doi. org/10.1177/0042098015624870

Chang, S. E., and M. Shinozuka. 2004. Measuring improvements in the disaster resilience of communities. Earthquake Spectra 20 (3):739-755. https://doi.org/10.1193/1.1775796

Chang, Y.-H., and C.-H. Yeh. 2001. Evaluating airline competitiveness using multiattribute decision making. Omega 29 (5):405-415. https://doi.org/10.1016/s0305-0483(01)00032-9

Chen. G.-H., and M.-J. Li. 2004. The research on the comprehensive evaluation method integration based on method set. Chinese Journal of Management Science (14):20-23.
Cheng, X., C. Shuai, J. Liu, J. Wang, Y. Liu, W. Li, and J. Shuai. 2018. Modelling environment and poverty factors for sustainable agriculture in the Three Gorges Reservoir Regions of China. Land Degradation and Development 29(11):3940-3953. https://doi. org/10.1002/ldr.3143

Cimellaro, G. P., C. Renschler, A. M. Reinhorn, and L. Arendt. 2016. PEOPLES: a framework for evaluating resilience. Journal of Structural Engineering 142(10):04016063. https://doi. org/10.1061/(ASCE)ST.1943-541X.0001514

Cutter, S. L. 2016. The landscape of disaster resilience indicators in the USA. Natural Hazards 80(2):741-758. https://doi. org/10.1007/s11069-015-1993-2

Cutter, S. L., K. D. Ash, and C. T. Emrich. 2014. The geographies of community disaster resilience. Global Environmental Change 29:65-77. https://doi.org/10.1016/j.gloenvcha.2014.08.005

Cutter, S. L., L. Barnes, M. Berry, C. Burton, E. Evans, E. Tate, and J. Webb. 2008. A place-based model for understanding community resilience to natural disasters. Global Environmental Change 18:598-606. https://doi.org/10.1016/j.gloenvcha.2008.07.013

Cutter, S. L., C. G. Burton, and C. T. Emrich. 2010. Disaster resilience indicators for benchmarking baseline conditions. Journal of Homeland Security and Emergency Management 7 (1):1-22. https://doi.org/10.2202/1547-7355.1732

Damm, M. 2010. Mapping social-ecological vulnerability to flooding. A sub-national approach for Germany. Dissertation. Rheinischen Friedrich-Wilhelms-Universität, Bonn, Germany. [online] URL: http://hss.ulb.uni-bonn.de/2010/1997/1997.pdf

Duncan, J. M., E. L. Tompkins, J. Dash, and B. Tripathy. 2017. Resilience to hazards: rice farmers in the Mahanadi Delta, India. Ecology and Society 22(4):3. https://doi.org/10.5751/ES-09559-220403

Fekete, A., G. Hufschmidt, and S. Kruse. 2014. Benefits and challenges of resilience and vulnerability for disaster risk management. International Journal of Disaster Risk Science 5 (1):3-20. https://doi.org/10.1007/s13753-014-0008-3

Folke, C. 2006. Resilience: the emergence of a perspective for social-ecological systems analyses. Global Environmental Change 16(3):253-267. https://doi.org/10.1016/j.gloenvcha.2006.04.002

Frankenberg, E., B. Sikoki, C. Sumantri, W. Suriastini, and D. Thomas. 2013. Education, vulnerability, and resilience after a natural disaster. Ecology and Society 18(2):16. https://doi. org/10.5751/ES-05377-180216

Galindo, G., and R. Batta. 2013. Review of recent developments in or/ms research in disaster operations management. European Journal of Operational Research 230(2):201-211. https://doi. org/10.1016/j.ejor.2013.01.039

Gautam, D. 2017. Assessment of social vulnerability to natural hazards in Nepal. Natural Hazards and Earth System Sciences 17 (12):2313-2320. https://doi.org/10.5194/nhess-17-2313-2017

Guo, X. G. 1995. A new comprehensive evaluation methodcombination evaluation method. Statistical Research 12 (5):56-59.

Guo, Y. J., Z. F. Ma, and F. M. Zhang. 2009. Validity analysis of several kinds of combination evaluation methods [J]. Chinese Journal of Management Science 2(17):125-130. 
Hahn, M. B., A. M. Riederer, and S. O. Foster. 2009. The livelihood vulnerability index: a pragmatic approach to assessing risks from climate variability and change-a case study in Mozambique. Global Environmental Change 19(1):74-88. https:// doi.org/10.1016/j.gloenvcha.2008.11.002

Huang, L., L.-H. Cai, and X.-J. Lan. 2015. An empirical study on the relationship between logistics and regional economic growth in the Three Gorges Reservoir Area-a case study of Wanzhou District, Chongqing. Journal of Guangxi University of Economic Management (3):92-97.

Huong, N. T. L., S. Yao, and S. Fahad. 2019. Assessing household livelihood vulnerability to climate change: the case of Northwest Vietnam. Human and Ecological Risk Assessment: An International Journal 25(5):1157-1175. https://doi. org/10.1080/10807039.2018.1460801

Hwang, C.-L., and K. Yoon. 1981. Multiple attribute decision making: methods and applications. Springer, Berlin, Germany.

Jiang, Q. Y. 2012. The comparative study of several main methods in the applications for multiple attribute decision making. Mathematical Modeling and its Application (3):16-28. [online] URL: http://www.cnki.com.cn/Article/CJFDTotal-QXYY201203003. $\underline{\mathrm{htm}}$

Kamal, A. S. M. M., M. Shamsudduha, B. Ahmed, S. M. K. Hassan, M. S. Islam, I. Kelman, and M. Fordham. 2018. Resilience to flash floods in wetland communities of northeastern Bangladesh. International Journal of Disaster Risk Reduction 31:478-488. https://doi.org/10.1016/j.ijdrr.2018.06.011

Kelman, I., J. C. Gaillard, J. Lewis, and J. Mercer. 2016. Learning from the history of disaster vulnerability and resilience research and practice for climate change. Natural Hazards 82(1):129-143. https://doi.org/10.1007/s11069-016-2294-0

Kittinger, J. N., K. M. Coontz, Z. Yuan, D. Han, X. Zhao, and B. A. Wilcox. 2009. Toward holistic evaluation and assessment: linking ecosystems and human well-being for the Three Gorges Dam. EcoHealth 6(4):601-613. https://doi.org/10.1007/s10393-010-0285-2

Kotzee, I., and B. Reyers. 2016. Piloting a social-ecological index for measuring flood resilience: a composite index approach. Ecological Indicators 60:45-53. https://doi.org/10.1016/j. ecolind.2015.06.018

Kythreotis, A. P., and G. I. Bristow. 2017. The 'resilience trap': exploring the practical utility of resilience for climate change adaptation in UK city-regions. Regional Studies 51 (10):1530-1541. https://doi.org/10.1080/00343404.2016.1200719

Li, L., and F.-Z. Wang. 2012. Research on evaluation of railway emergency plan based on improved VIKOR method. Chinese Journal of Safety Science 22(8):30-37.

Liu, X., H. Guo, Y. Li, Y. Li, and W. Pan. 2016. Measuring the urban competitiveness of Chinese cities based on multi-attribute decision making approach. International Journal of Sustainable Development 19(4):315. https://doi.org/10.1504/IJSD.2016.080505

Liu, X., H. Guo, Y.-R. Lin, Y. Li, and J. Hou. 2018. Analyzing spatial-temporal distribution of natural hazards in China by mining news sources. Natural Hazards Review 19(3):04018006. https://doi.org/10.1061/(ASCE)NH.1527-6996.0000291
Liu, Y., K. Yin, L. Chen, W. Wang, and Y. Liu. 2016. A community-based disaster risk reduction system in Wanzhou, China. International Journal of Disaster Risk Reduction 19:379-389. https://doi.org/10.1016/j.ijdrr.2016.09.009

Lu, X. L. 2018. Economic characteristics of population in the Three Gorges Reservoir Area and development countermeasures. Contemporary Economics (5):16-19. [online] URL: http://www. cnki.com.cn/Article/CJFDTotal-DAJJ201805005.htm

Ma, J., C. X. Li, H. Wei, P. Ma, Y. J. Yang, Q. S. Ren, and W. Zhang. 2015. Dynamic evaluation of ecological vulnerability in the Three Gorges Reservoir region in Chongqing municipality, China. Acta Ecologica Sinica 35(21):7117-7129. https://doi. org/10.5846/stxb201309252364

Manyena, S. B. 2006. The concept of resilience revisited. Disasters 30(4):434-450. https://doi.org/10.1111/j.0361-3666.2006.00331.x

Mayunga, J. S. 2007. Understanding and applying the concept of community disaster resilience: a capital-based approach. Summer Academy for Social Vulnerability and Resilience Building 1 (1):1-16. [online] URL: https://www.u-cursos.cl/usuario/3b514b53bcb4025aaf9a6781047e4a66/mi_blog/r/11. Joseph_S. Mayunga. pdf

Meerow, S., J. P. Newell, and M. Stults. 2016. Defining urban resilience: a review. Landscape and Urban Planning 147:38-49. https://doi.org/10.1016/j.landurbplan.2015.11.011

Ministry of Environmental Protection of the People's Republic of China (MEP). 2017. Bulletin on the ecological and environmental monitoring results of the Three Gorges Project. Ministry of Ecology and Environment of the People's Republic of China, Beijing, China. [online] URL: http://english.mee.gov. cn/Resources/Reports/threegorgesbulletin/201805/ P020180531671455848589.pdf

National Infrastructure Advisory Council (NIAC). 2009. Critical infrastructure resilience: final report and recommendations. National Infrastructure Advisory Council, Washington, D.C., USA. [online] URL: https://www.cisa.gov/sites/default/files/ publications/niac-critical-infrastructure-resilience-finalreport-09-08-09-508.pdf

Norris, F. H., S. P. Stevens, B. Pfefferbaum, K. F. Wyche, and R. L. Pfefferbaum. 2008. Community resilience as a metaphor, theory, set of capacities, and strategy for disaster readiness. American Journal of Community Psychology 41(1-2):127-150. https://doi.org/10.1007/s10464-007-9156-6

Opricovic, S., and G.-H. Tzeng. 2004. Compromise solution by MCDM methods: a comparative analysis of VIKOR and TOPSIS. European Journal of Operational Research 156 (2):445-455. https://doi.org/10.1016/S0377-2217(03)00020-1

Peng, L., D. Xu, and X. Wang. 2019. Vulnerability of rural household livelihood to climate variability and adaptive strategies in landslide-threatened western mountainous regions of the Three Gorges Reservoir Area, China. Climate and Development 11:469-484. https://doi.org/10.1080/17565529.2018.1445613

Peng, L., S. Liu, and L. Sun. 2016b. Spatial-temporal changes of rurality driven by urbanization and industrialization: a case study of the Three Gorges Reservoir Area in Chongqing, China. 
Habitat International 51:124-132. https://doi.org/10.1016/j. habitatint.2015.10.021

Peng, Z., Z. Qiang, S. Wang, and S. Yang. 2016a. Research on a recombination evaluation approach based on the previous evaluation results. Chinese Journal of Management Science 24 (9):156-164.

Razafindrabe, B. H. N., G. A. Parvin, A. Surjan, and R. Shaw. 2009. Climate disaster resilience: focus on coastal urban cities in Asia. Asian Journal of Environment and Disaster Management 1 (1):1-15. https://doi.org/10.3850/S179392402009000088

Renaud, F. G., K. Sudmeier-Rieux, and M. Estrella. 2013. The role of ecosystems in disaster risk reduction. United Nations University Press, Tokyo, Japan.

Renaud, F. G., K. Sudmeier-Rieux, M. Estrella, and U. Nehren. 2016. Ecosystem-based disaster risk reduction and adaptation in practice (Vol. 42). Springer, Berlin, Germany. https://doi. org/10.1007/978-3-319-43633-3

Rus, K., V. Kilar, and D. Koren. 2018. Resilience assessment of complex urban systems to natural disasters: a new literature review. International Journal of Disaster Risk Reduction 31:311-330. https://doi.org/10.1016/j.ijdrr.2018.05.015

Saja, A. M. A., A. Goonetilleke, M. Teo, and A. M. Ziyath. 2019. A critical review of social resilience assessment frameworks in disaster management. International Journal of Disaster Risk Reduction (35):101096. https://doi.org/10.1016/j.ijdrr.2019.101096

Shi, Z. L., and Y. Y. Yang. 2009. Analysis of factors influencing economic recovery of involuntary migration - a comparative study on migration between the Three Gorges Reservoir area and Danjiangkou Reservoir area. Population Research 33(1):72-80.

Stone, R. 2008. China's environmental challenges. Three Gorges Dam: into the unknown. Science 321(5889):628-632. https://doi. org/10.1126/science.321.5889.628

Tan, Y., and F. Yao. 2006. Three Gorges project: effects of resettlement on the environment in the reservoir area and counter measures. Population and Environment 27(4):351-371. https://doi. org/10.1007/s11111-006-0027-0

Tang, J., and M. Q. Zhang. 2009. Validity analysis of three combination evaluation methods. Computer Engineering and Design 30(15):3568-3572.

Tilt, B., Y. Braun, and D. He. 2009. Social impacts of large dam projects: a comparison of international case studies and implications for best practice. Journal of Environmental Management 90:S249-S257. https://doi.org/10.1016/j.jenvman.2008.07.030

Tilt, B., and D. Gerkey. 2016. Dams and population displacement on China's Upper Mekong River: implications for social capital and social-ecological resilience. Global Environmental Change 36:153-162. https://doi.org/10.1016/j.gloenvcha.2015.11.008

United Nations International Strategy for Disaster Reduction (UNISDR). 2009. Terminology on disaster risk reduction. United Nations, Geneva, Switzerland. [online] URL: https://reliefweb. int/sites/reliefweb.int/files/resources/Full Report 2010.pdf

United Nations International Strategy for Disaster Reduction (UNISDR). 2015. Sendai framework for disaster risk reduction
2015-2030. United Nations International Strategy for Disaster Reduction, Geneva, Switzerland. [online] URL: https://www. preventionweb.net/files/43291 sendaiframeworkfordrren.pdf

Wagner, I., and P. Breil. 2013. The role of ecohydrology in creating more resilient cities. Ecohydrology and Hydrobiology 13 (2):113-134. https://doi.org/10.1016/j.ecohyd.2013.06.002

Wallemacq, P. 2018. Economic losses, poverty and disasters: 1998-2017. Centre for Research on the Epidemiology of Disasters, Brussels, Belgium. [online] URL: https://reliefweb.int/sites/ reliefweb.int/files/resources/61119 credeconomiclosses 0.pdf

Wang, X., and E. Triantaphyllou. 2008. Ranking irregularities when evaluating alternatives by using some ELECTRE methods. Omega 36(1):45-63. https://doi.org/10.1016/j.omega.2005.12.003

World Bank. 1994. World development report 1994: infrastructure for development: executive summary. World Bank, Washington, D.C., USA. https://doi.org/10.1596/978-1-4648-0484-7_world_development report

Xu, D., L. Peng, S. Liu, C. Su, X. Wang, and T. Chen. 2017. Influences of migrant work income on the poverty vulnerability disaster threatened area: a case study of the Three Gorges Reservoir Area, China. International Journal of Disaster Risk Reduction 22:62-70. https://doi.org/10.1016/j.ijdrr.2017.03.001

Yan, H., J. Zhan, B. Liu, W. Huang, and Z. Li. 2014. Spatially explicit assessment of ecosystem resilience: an approach to adapt to climate changes. Advances in Meteorology 2014:1-9. https://doi. org/10.1155/2014/798428

Yang, W., K. Xu, J. Lian, C. Ma, and L. Bin. 2018. Integrated flood vulnerability assessment approach based on TOPSIS and Shannon entropy methods. Ecological Indicators 89:269-280. https://doi.org/10.1016/j.ecolind.2018.02.015

Zanakis, S. H., A. Solomon, N. Wishart, and S. Dublish. 1998. Multi-attribute decision making: a simulation comparison of select methods. European Journal of Operational Research 107 (3):507-529. https://doi.org/10.1016/S0377-2217(97)00147-1

Zhang, M. S., and H. H. Li. 2018. Review of urban resilience assessment in the context of climate change. Ecological Economy 34(10):154-161. [online] URL: http://www.cnki.com.cn/Article/ CJFDTotal-STJJ201810029.htm

Zhou, L. M. 2016. Resilient city: risk governance and index construction -- a discussion on international cases. Journal of Beijing University of Administration (2):13-20. [online] URL: http://www.cnki.com.cn/Article/CJFDTotal-XZXY201602003.htm

Zhou, Y., J. Qiu, X. Wang, G. Lin, and Q. Wu. 2010. A vulnerability assessment of landslide in water-level-fluctuation zones of the Three Gorges Reservoir. Resources Science 32 (7):1301-1307.

Zou, Z.-H., Y. Yun, and J.-N. Sun. 2006. Entropy method for determination of weight of evaluating indicators in fuzzy synthetic evaluation for water quality assessment. Journal of Environmental Sciences (China) 18(5):1020-1023. https://doi. org/10.1016/S1001-0742(06)60032-6 